\title{
DA LOUCURA AO CRIME - UMA ANÁLISE CRÍTICA DOS TRATAMENTOS PENAIS E PSICOLÓGICOS PARA CRIMINOSOS SOCIOPATAS
}

\author{
João Fernando Fank* \\ Carina Gaelzer Silva Torres** \\ Charlon Luis Zalewski*** \\ Leonardo Miotti**** \\ Aline Librelotto Rubin***** \\ Ivy Catherine Bueno Roth******
}

RESUMO: Há muito se discute a problemática das penas em face dos criminosos incapazes. Este artigo versa especificamente sobre a categoria de criminoso popularmente conhecido como "sociopata". É largamente sabido que as medidas de segurança visam a chamada "prevenção específica”, ou seja, evitar que o delinqüente volte a cometer fatos delitivos. Evitando criticar as características prisionais do sistema de internamento atual, este artigo procura demonstrar que este modelo de tratamento não é eficaz com o "sociopata" da mesma forma como seria com outros pacientes, estes apresentando distúrbios "fisiológicos" ou "orgânicos", como a epilepsia ou transtorno esquizofreniforme.

PALAVRAS-CHAVES: Criminosos sociopatas. Medida de segurança. Eficácia preventiva.

ABSTRACT: The problem of the punishmen for incapable criminals has been discussed for long. This article deals specifically with those criminals popularly known as "sociopaths". It's widely known that security measures aim at the so called specific prevention, i.e., avoiding the felon from committing any offences again. Escaping from criticizing the incarcerating characteristics of the modern system, this article attempts to demonstrate that such a treatment model is not efficacious towards the "sociopath" as it would be with other patients, those which present "physiological" or "organic" disturbances, such as epilepsy or schizophrenia.

KEY-WORDS: Sociopath felons. Security measures. Preventive efficacy.

* Acadêmico do $4^{\circ}$ semestre do Curso de Direito da Universidade Federal de Santa Maria

**Acadêmica do $4^{\circ}$ semestre do Curso de Direito da Universidade Federal de Santa Maria

***Acadêmico do $4^{\circ}$ semestre do Curso de Direito da Universidade Federal de Santa Maria

*****Acadêmico do $4^{\circ}$ semestre do Curso de Psicologia da Universidade Federal de Santa Maria

******Acadêmicado $4^{\circ}$ semestre do Curso de Psicologia da Universidade Federal de Santa Maria

******Acadêmica do $4^{\circ}$ semestre do Curso de Direito da Universidade Federal de Santa Maria 


\section{INTRODUÇÃO}

Não raramente encontramo-nos com casos de criminosos aparentemente desprovidos de qualquer sentimento social. São casos de crimes que chocam por sua extrema violência, crueldade ou simplesmente ausência de qualquer demonstração de culpa por parte de quem os cometeu.

Tal comportamento, normalmente associado aos famigerados assassinos em série, imortalizados por inúmeros filmes e livros, pode ser encontrado, também, em delitos mais comuns, e fatos muito menos notáveis.

Isso porque se trata aqui de criminosos que não são definidos por seus atos e sim pelo distúrbio que carregam: Transtorno de Personalidade Anti-Social (TPAS), popularmente chamado de "sociopatia" ou "personalidade psicopática". Tal fato significa dizer que esse tipo de criminoso é, atualmente, configurado como um ser humano portador de patologia de ordem psiquiátrica.

Deve-se, a partir das considerações acima, fazer a seguinte pergunta: há previsão específica para esse tipo de criminoso - aparentemente intratável, como se demonstrará na legislação brasileira?

A resposta, infelizmente, é negativa. A legislação brasileira os trata do mesmo modo que outros criminosos afetados por doença mental, estas de ordem biológica, sendo considerados, via de regra, como semi-imputáveis. Tal classificação é dada pela perícia realizada normalmente em Institutos Psiquiátricos Forenses e encaminhada ao juiz do caso, que decidirá sobre o futuro do criminoso com TPAS.

Está em sua margem de discricionariedade decidir por encaminhar o réu com Transtorno de Personalidade Anti-Social à prisão, na qual cumprirá sua pena como qualquer outro criminoso (ainda que com algumas particularidades), ou a uma instituição como os Institutos Psiquiátricos Forenses (IPF), onde será submetido a uma medida de segurança.

O que se questiona, contudo, é a real eficácia de ambas as opções, frente a criminosos que se mostram, aparentemente, imunes a seus objetivos e métodos, de forma a ser imperativa análise mais profunda dos institutos, suas implicações e teorias, bem como suas conseqüências e efeitos (ou falta dos mesmos) em criminosos com TPAS.

\section{O NORMAL E O PATOLÓGICO}


Ao fazermos uma relação entre a experimentação e a doença mental, Lagache não admite a identificação da doença com a experimentação. Ele afirma que uma experimentação exige uma análise exaustiva das condições de existência do fenômeno e uma rigorosa determinação das condições que se faz variar para observar suas incidências. Em nenhum desses pontos a doença mental é compatível com a experimentação.

Como primeiro ponto, ele afirma, no relato de Georges Canguilhem, que "nada é mais desconhecido do que as condições nas quais a natureza institui essas experiências, as doenças mentais: o início de uma psicose escapa quase sempre ao médico, ao paciente, aos que com ele convivem; a fisiopatologia, a anatomopatologia desse processo são obscuras". ${ }^{1}$ A seguir, afirma: "no fundo da ilisão que identifica o método patológico em psicologia com o método experimental, há a representação atomística e associanista da vida mental, há a psicologia das faculdades". ${ }^{2}$ Ribot, no entanto possui uma posição totalmente diferente a de Lagache. Segundo aquele, a doença - substituto espontâneo e metodologicamente equivalente de experimentação - atinge o inacessível, mas respeita a natureza dos elementos normais nos quais ela compõe as funções psíquicas. A doença desorganiza mas não transforma, revela sem alterar.

Ao discutirmos acerca dos métodos de diagnóstico e identificação dos transtornos, o primeiro passo a ser dado é realizar a distinção entre o normal e do patológico. É de importância sabermos até onde se estende a linha que demarca os limites do normal, além do enquadramento do sujeito em questão em um dos dois lados desta fronteira. $\mathrm{O}$ alicerce do diagnóstico do transtorno mental é a definição da fronteira entre o normal e o patológico.

\subsection{Dos transtornos psicológicos em pauta}

O sujeito na situação de conflito se expressa em condutas que causam o sofrimento alheio na forma de agressão e infração da lei. No contexto psicanalítico de perversão, isso se forma através do Complexo de Édipo, que tem função de estruturação do funcionamento psíquico do indivíduo. Nesses sujeitos, a castração, que ocorre no Complexo de Édipo, tendo a finalidade de ditar a lei e oferecer uma organização ao sujeito que responda aos moldes sociais e éticos, aparentemente não ocorre. $\mathrm{Na}$ sociopatia, um tipo de perversão, acontece uma falha nesse processo de castração e, por

\footnotetext{
${ }^{1}$ CANGUILHEM, Georges. O normal e o patológico. Ed. Forense Universitária. São Paulo, SP, 2001, p. 66 
conseqüência, a formação um Superego falho, que vai incidir diretamente sobre a percepção do indivíduos acerca das leis que regem a convivência social.

É de relevância o esclarecimento psicanalítico entre os quadros de "perversão" e "psicose", pois é essencial o entendimento de que o transtorno psicológico dos sujeitos em pauta se encontra na área da perversão, e não da psicose, podendo-se confundir psicopatas com sociopatas. O processo de saída do Complexo de Édipo delineia a linha do normal e patológico, a forma com que o indivíduo enfrenta a castração será o definidor para a possibilidade de desenvolvimento de um quadro patologico de psicose ou perversão.

A rejeição ou forclusão da castração pelo indivíduo é o principal estruturante da psicose. É o que afirma Freud "pode estabelecer-se um processo que eu gostaria de chamar de rejeição, processo que, na vida mental das crianças, não aparece incomum nem muito perigoso, mas em um adulto significaria o começo de uma psicose". ${ }^{3}$

Já a perversão se caracteriza pela negação da castração, em que o indivíduo usa do fetiche para encobrir a castração que foi negada. Os perversos, então, não pessoas que não se submeteram a lei da castração imposta pelo Édipo e, consequentemente, não se submeterão a nenhum outro tipo de lei ou regra. Além disso, por causa da falta da introjeção da lei, também são incapazes de sentir culpa.

Filho de mãe alemã e pai afegão, Assef era louro, de olhos azuis e bem mais alto que todos os outros garotos. Sua merecida fama de atos de selvageria o precedia pela rua (...) Sua palavra era lei e se por acaso você precisasse de alguma instrução legal, aquele soco-inglês metálico era o instrumento ideal para ele lhe transmitir os seus ensinamentos. Uma vez vi Assef usar o soco-inglês em um menino do bairro de Karteh-Char. Nunca vou esquecer como os seus olhos azuis brilhavam com uma luz não inteiramente sã e, como ele sorria, sim, como sorria enquanto esmurrava o pobre garoto inconsciente. (...) Anos mais tarde, aprendi uma palavra que define muito bem uma criatura como Assef, uma palavra para a qual não existe um equivalente perfeito em farsi: Sociopata. ${ }^{4}$

Como se verifica pelo trecho transcrito supra, Hosseini mostra que esse tipo de personalidade criminosa está presente também na literatura de massa atual. Assef, o garoto do trecho anteriormente citado apresenta o perfil de um potencial sociopata, em vista da descrição de seus comportamentos. O caso da Sociopatia é descrito pela DSMIV, importante manual de diagnóstico usado por psicólogos e psiquiatras, como um Transtorno de Personalidade Anti-Social. A Organização Mundial de Saúde, porém, na 
sua classificação de doenças (CID-10) define usando o termo "Distúrbio de Personalidade Dissocial".

Todas essas definições para a Sociopatia descrevem indivíduos que desprezam as obrigações sociais e possuem falta de empatia com os outros, estabelecendo um desvio entre a sua maneira de agir e as normas sociais estabelecidas. Eles apresentam, entre várias outras características, um egocentrismo patológico, baixa tolerância para frustração e ausência de remorso e sentimento de culpa. Por causa dessa ultima característica, os sociopatas são pessoas incapazes de apreender o objetivo da punição.

$A$ presença de um superego estruturado de forma primitiva e sádica impedem-no de vivenciar algo como uma ansiedade de natureza depressiva, o que está na base da estruturação de qualquer sistema de valores éticos e moral, que considera os danos potencialmente causados ao outro pelas atitudes do sujeito. É nesta incapacidade do TPAS [Transtorno de personalidade anti-social] que reside a sua intratabilidade. ${ }^{5}$

O encaminhamento médico-legal de casos em que o indivíduo é portador desse distúrbio é feito através do diagnostico baseado no DSM, que classifica a patologia como Transtorno de Personalidade Anti-Social.

A partir do progressivo predomínio do DSM (com sua visão propositadamente ateorética e descritiva) como instrumento uniformizador da expressão pericial, os achados mais subjetivos ligados ao diagnóstico de Transtorno De Personalidade Anti-Social foram sendo obscurecidos e substituídos pela mera fenomenologia. O evidente empobrecimento diagnóstico reflete-se, por exemplo, na quase equiparação de conduta criminosa repetitiva e TPAS, o que resultou em inúmeros diagnósticos falso-positivos. ${ }^{6}$

\section{O TRATAMENTO LEGISLATIVO DO ASSUNTO}

Feito o laudo psicológico pela equipe competente, cabe ao juiz, segundo o art. 26 do Código Penal Brasileiro, a decisão entre duas opções [considerando-se, obviamente, que o réu agiu conforme a conduta típica]: aplicação de pena, seja ela privativa de liberdade, restritiva de direitos ou de multa ou aplicação de medida de segurança.

Interessa-nos aqui, em princípio, a verificação do segundo instituto. Entretanto, para tal intuito, é importante a verificação dos fundamentos também da pena.

\section{A MEDIDA DE SEGURANÇA - ASPECTOS TÉCNICOS:}

\footnotetext{
${ }^{5}$ SOUZA, Carlos Alberto Crespo de; CARDOSO, Rogério Göttert. Psiquiatria Forense - 80 anos de prática institucional. Ed. Sulina. 2006. Porto Alegre, RS, p. 266

${ }^{6}$ SOUZA, Carlos Alberto Crespo de; CARDOSO, Rogério Göttert. Psiquiatria Forense - 80 anos de prática institucional. Ed. Sulina. 2006. Porto Alegre, RS, p. 263
} 
Segundo expressam os arts. 96 e 97 do Código Penal Brasileiro:

Art. 96. As medidas de segurança são:

I - Internação em hospital de custódia e tratamento psiquiátrico ou, à falta, em outro estabelecimento adequado;

II - sujeição a tratamento ambulatorial. Parágrafo único - Extinta a punibilidade, não se impõe medida de segurança nem subsiste a que tenha sido imposta.

\section{Imposição da medida de segurança para inimputável}

Art. 97 - Se o agente for inimputável, o juiz determinará sua internação (art. 26). Se, todavia, o fato previsto como crime for punível com detenção, poderá o juiz submetê-lo a tratamento ambulatorial.

\section{Prazo}

$\S 1^{\circ}$ - A internação, ou tratamento ambulatorial, será por tempo indeterminado, perdurando enquanto não for averiguada, mediante perícia médica, a cessação de periculosidade. O prazo mínimo deverá ser de 1 (um) a 3 (três) anos.

Alude, também, Fernando Capez:

Conceito: sanção penal imposta pelo Estado, na execução de uma sentença, cuja finalidade é exclusivamente preventiva, no sentido de evitar que o autor de uma infração penal que tenha demonstrado periculosidade volte a delinqüir. ${ }^{7}$

Ou seja, feito o laudo psiquiátrico e apresentadas as conclusões ao julgador, cabe a este decidir, para os casos de criminosos com TPAS, de forma alternativa à pena mas desta excludente [vez que o Brasil, atualmente adota o sistema vicariante, ou seja, ou aplica-se pena ou medida de segurança], uma medida de segurança, visando a, principalmente, controlar a possível periculosidade do agente e colocar-lhe em tratamento.

Por periculosidade deve-se entender o potencial apresentado pelo autor do delito para cometer novos atos ilícitos. Nos casos dos criminosos com TPAS, contudo, deve-se lembrar que a periculosidade figura quase como um sintoma do distúrbio.

Como já referido nos artigos mencionados do $\mathrm{CP}$, sendo a medida de segurança do tipo detentivo, irá o réu cumpri-la em hospital de custódia e tratamento psiquiátrico, como é, por exemplo, o Instituto Psiquiátrico Forense de Porto Alegre. Se for do tipo restritivo, terá caráter ambulatorial, prescindindo, portanto, de internação.

Deve-se compreender, especialmente, que a medida de segurança não é pena. É, sim, aplicada a agentes inimputáveis ou semi-imputáveis [caso dos criminosos com TPAS], de forma que, não se podendo falar em imputabilidade, não há sequer que se falar em punibilidade, quanto mais em pena.

Ainda assim, conforme anota Sérgio Carrara, sobre impressão retirada do IPF do Rio de Janeiro (1998):

${ }^{7}$ CAPEZ, Fernando. Curso de Direito Penal - Parte Geral. 10ª Edição. Ed Saraiva. 2006, São Paulo, SP, p. 231 
Absolutamente notável, à primeira vista, era o fato de os internos quase sempre se dizerem 'presos', e não 'doentes', ou de se referirem à sua estada no MJ quase sempre como uma 'pena', e nunca como um 'tratamento'. ${ }^{8}$

Isso porque, pertencendo ao sistema prisional brasileiro, os institutos psiquiátricos forenses possuem cotidiano rígido, presença de guardas, entre outros aspetos. Além disso, a internação também é, de certa forma, perda da liberdade. Contudo, uma análise crítica a respeito do instituto, especialmente no que concerne aos criminosos com Transtorno de Personalidade Anti-Social, será feita mais adiante.

Por fim, deve ser ressaltado que, além da diferença de objetivos com relação às penas [mesmo tendo também o caráter preventivo, a medida de segurança procura alcançar tal meta mediante o tratamento e não mero confinamento], há também uma diferença no que concerne ao prazo.

Enquanto no sistema penal brasileiro, só é possível que um cidadão cumpra pena de prisão por, no máximo, trinta anos, a medida de segurança apresenta apenas prazo mínimo.

É o que expressa Fernando Capez (2006):

Medida de Segurança detentiva: possui a seguintes características:

a) é obrigatória quando a pena imposta for a de reclusão;

b) será por tempo indeterminado, perdurando enquanto não for averiguada, mediante perícia médica, a cessação da periculosidade;

c) a cessação da periculosidade será averiguada após um prazo mínimo, variável entre um e 3 anos;

d) a averiguação pode ocorrer a qualquer tempo, mesmo antes do término do prazo mínimo, se o juiz da execução determinar (LEP, art. 176).

Desinternação: será sempre condicional, devendo ser restabelecida a situação anterior se o agente, antes do decurso de um ano, pratica fato indicativo de sua periculosidade [não necessariamente crime].

Dessa forma, verifica-se o quão grande é a necessidade de diferenciação entre pena e medida de segurança, vez que a pena de prisão perpétua é constitucionalmente proibida, por ser considerada atentatória aos direitos e garantias fundamentais do homem. Já no que concerne à medida de segurança, a estadia por tempo indefinido é uma possibilidade, em caso de não cessar a periculosidade do agente ou, uma vez desinternado, o mesmo vier a cometer ato que demonstre o potencial para cometer novos delitos.

${ }^{8}$ CARRARA, Sérgio. Crime e Loucura - O aparecimento do manicômio judiciário na passagem do século. Ed. UERJ. 1998, Rio de Janeiro, RJ, p. 19 


\section{DOS FUNDAMENTOS E FINS DAS PENAS E DA MEDIDA DE SEGURANÇA}

Anota Mário Cipriani:

Churchill já indicava que nada pode proporcionar uma percepção mais penetrante da vida sociocultural dos povos do que a sua jurisprudência criminal. A atitude das comunidades diante dos delitos, das antigas até hoje, assim igualmente a natureza e o castigo impostos aos delinqüentes, são os medidores que permitem, com precisão, avaliar o nível cultural de um povo e o grau de evolução de sua civilização. ${ }^{9}$

Devidamente ressaltada a importância do estudo das penas para o entendimento de uma sociedade, não cabe aqui discorrer sobre a evolução de seus conceitos. Os objetivos do presente projeto tornam imperativo que se restrinja o âmbito da análise aos conceitos modernos de sanção penal, seus fundamentos e fins.

Não podemos ignorar a existência de uma importante tentativa de construção da política-criminal a partir de perspectivas utilitaristas de eficiência. (...) Trata-se do intento de Von Liszt, acompanhado de outros autores da chamada 'linha moderna', os quais, como se poderá imaginar, partem de uma imagem de indivíduo diametralmente oposta à do delinqüente racional, eles lidam com o homo sociologicus. Sobre esse pretendem fazer recair as sanções do Direito Penal e, sobretudo, as medidas de segurança ressocializadoras, inocuizadoras ou intimidatórias, em função do tipo de delinqüente de que se trate, dadas sua personalidade e suas circunstâncias sociais. Concretamente, Von Liszt, em seu ensaio Der Zweckgedanke im Strafrecht (1882), defende que a pena justa é apenas a pena necessária. Em seu esquema, constata-se o fracasso da pena retributiva, indiferenciada, e a proposta de uma pena orientada a cada tipo de delinqüente: ressocializadora, intimidatória, inocuizadora. ${ }^{10}$

Em outras palavras, a pena como forma de retribuição falhou. Buscou-se, portanto, um novo fundamento para sua existência. A ênfase da Escola Positiva acerca do indivíduo "patológico", de sua inadaptabilidade individual/social e periculosidade foi uma das principais bases para o intento da medida de segurança e das penas preventivas, e seus objetivos “clínico-preventivos". É o que afirma Luis Flávio Gomes:

Diante da ineficácia do sistema punitivo em voga surge, como reação, protagonizada pela Escola Positiva, o incremento sancionatório da intervenção penal, dela fazendo parte desde então também as medidas de segurança. ${ }^{11}$

É importante verificar que a personalidade do autor do delito passou a destaque.

\footnotetext{
${ }_{9}^{9}$ CIPRIANI, Mário Luis Lírio. Das penas - suas teorias e funções no moderno direito penal. Ed. ULBRA, 2005, Canoas/RS, p. 1

${ }^{10}$ Ibidem, p. 15

${ }^{11}$ GOMES, Luis Flávio. Princípio da ofensividade no direito penal.Ed. RT. 2002, São Paulo, SP, p. 32
} 
Desde logo adotou-se a concepção sintomática de delito, isto é, o delito passou a ser concebido como sintoma de uma maneira de ser do sujeito que é percebido e reputado como perigoso e anormal. ${ }^{12}$

Dentre as finalidades da pena está a retribuição pelo ilícito cometido e a prevenção de novos delitos. Esta pode ser: geral - caráter intimidativo aos demais potenciais infratores; especial - a pena visa o autor do delito, retirando-o do meio social, impedindo-o de delinqüir e procurando corrigi-lo. Neste sentido, pontua Luiz Flávio Gomes a passagem da "concepção retributiva [imposição da pena ao delito conforme culpabilidade do seu autor] para a preventiva; da prevenção geral à especial [a pena existe para evitar a reincidência]". 13

De fato, a prevenção calcou-se não apenas nos conceitos da escola positiva, mas também na premente necessidade de oferecer à sociedade segurança contra a crescente criminalidade. Nesse quesito, importa notar a visão de Luiz Luisi, citado por Mário L. L. Cipriani:

Tanto a pena, clássica forma de sanção penal, como as modernas medidas de segurança, em todas as suas modalidades, pretendem, ao combater a delinqüência, realizar o propósito de garantir a seguridade social. A pena considerada como castigo visa retribuir o mal do crime para restabelecer o equilíbrio social e restaurar a segurança, violentada pelo crime. A pena entendida como modo de prevenção geral ou individual de novas infrações criminais objetiva e enfatiza a defesa social, de modo que, independentemente da sua função da pena, o direito penal terá sempre o escopo de ser o instrumento que concede a segurança social. ${ }^{14}$

De outra banda, a ciência penal funda a aplicação da pena na culpabilidade do agente, segundo a parcela majoritária da doutrina. Deste modo, os inimputáveis não devem sofrer pena, considerada como medida retributiva e preventiva. Não pode o Estado, entretanto, ignorar o cometimento do ilícito. Cabe, portanto, ao menor de idade, medida sócio-educativa. Ao delinqüente que, "por doença mental ou desenvolvimento mental incompleto ou retardado, era, ao tempo da ação ou da omissão, inteiramente incapaz de entender o caráter ilícito do fato ou de determinar-se de acordo com esse entendimento" "15, não é possível, também, imputar sanção de caráter retributivo. Persiste, entretanto, o objetivo primordial da sanção penal: promover a segurança social.

\footnotetext{
${ }^{12}$ Ibidem, p. 34

${ }^{13}$ Ibidem, p. 39

${ }^{14}$ CIPRIANI, Mário Luis Lírio. Das penas - suas teorias e funções no moderno direito penal. Ed. ULBRA, 2005, Canoas/RS, p. 51

${ }^{15}$ BITENCOURT, Cezar Roberto. Tratado de Direito Penal, volume 1. Ed. Saraiva, 2007, São Paulo/SP, p. 689
} 
Deste modo, enquanto "as penas têm caráter retributivo-preventivo, as medidas de segurança têm natureza eminentemente preventiva." 16

A medida de segurança "encontra justificativa somente na periculosidade aliada à incapacidade penal do agente." 17 Em outras palavras, enquanto o fundamento da aplicação da pena é a culpabilidade, a medida de segurança fundamenta-se exclusivamente na periculosidade. $\mathrm{O}$ criminoso que apresente TPAS deve, pelo perigo que representa à ordem social, consubstanciado no crime cometido, ser contido por meio da medida de segurança, e, quando possível, receber adequado tratamento, de modo a eliminar a ameaça por ele representada. É por esse motivo que a medida de segurança "vige por tempo indeterminado, até que cesse a periculosidade, constatada através de perícia médica (art. 97, $\$ 1^{\circ}$ do CP).”18

\section{ANÁliSE CRÍTICA ACERCA DA MEDIDA DE SEGURANÇA - A CRIMINOLOGIA E A COMPREENSÃO PSICOLÓGICA DA QUESTÃO}

Na maioria das vezes em que se pensa no sistema penal, a questão da análise do indivíduo, sob o ponto de vista psicológico, faz-se mister. Além de todo o arcabouço teórico da proteção da sociedade, da busca da convivência social pacífica, da punição àquele que infringe as normas legais, da mentença da ordem, etc., característico da Ciência Penal, é importante que se analise aquele que se torna personagem dessas discussões.

A Escola Positiva trouxe a possibilidade de pensarmos as contingências psíquicas daquele que delinqüe, trazendo a sanidade mental como pressuposto da aplicação de medidas de segurança. Estas são o próprio reflexo dessa busca de tratar o indivíduo em sua saúde mental, embora, segundo Bitencourt, não seja possível pretender que a readaptação social seja uma responsabilidade exclusiva das disciplinas penais. Elas não estão, entretanto, eximidas deste objetivo. ${ }^{19}$

Um dos objetivos das penas, além de punir, seria a posterior ressocialização do indivíduo. Autores, como Bitencourt chegam a chamá-la de mito. É de se duvidar sim, cada vez mais, em vistas da precariedade de nosso sistema prisional, da finalidade citada. A pena privativa de liberdade, ao que parece, age num contra-senso: retira o individuo da sociedade livre, ou seja, incorre numa "dessocialização". Tal é a veemente crítica, muito plausível, acerca de nosso sistema penal.

\footnotetext{
${ }_{17}^{16}$ Idem.

${ }^{17}$ Idem.

${ }^{18}$ Ibidem, p. 697

${ }^{19}$ Ibidem, p. 685
} 
Pode-se pensar que com a medida de segurança não é diferente. Revestida de uma nominação um pouco mais branda, não deixa de ser uma pena de privação de liberdade, no caso da espécie detentiva, mas com outra "roupagem".

Uma análise terminológica já sugere a idéia de proteção, prevenção. Mas própria pena privativa de liberdade também tem esse intento. Mas segurança para quem: para o indivíduo [de si mesmo] ou para o resto da sociedade? A sistemática compreensiva sugere as duas e por isso, em tal residiria um possível mérito da medida de segurança: buscar, diretamente, a "cura" e a recuperação da pessoa em suas normais faculdades mentais.

A redação do Art.26 do Código Penal fala de "doença mental ou desenvolvimento mental incompleto ou retardado, da incapacidade do indivíduo entender a sua ação...”, essa é a presunção para a inimputabilidade. Nada mais explícito, portanto, do que essa redação para mostrar a ingerência da Psicologia na ciência Penal. A discricionariedade do julgador ao apreciar essa possibilidade, pelas circunstancias objetivas e subjetivas da ação cometida é imensa. E, aqui, surge um questionamento: o que seria um indivíduo normal, com desenvolvimento mental completo e situado em suas faculdades psíquicas? Com que conhecimento o avaliador procede nessa análise, somente com a práxis jurídica [certamente não]? Com que autoridade o cientista penal diferencia o normal do patológico, se mesmo os cientistas especializados têm dificuldade em fazê-lo? Ressalvados as particularidades relativas de cada pessoa humana, um padrão mínimo de conduta social é aceito, baseado num ser racional, que se orienta, de certa forma, pela ordem lógica da linha espaço-temporal-cultural de determinada comunidade humana.

Outra questão referente ao ser "anormal" é destacada: tem-se o anormal patológico, com disfunções biológico-mentais; e o "patológico social", o criminoso com TPAS, objeto deste estudo, espécie de sociopata, aquele que, afastada uma concreta debilidade mental, apresenta-se como um "anti-social”, figura dúplice por ser anormal porém não doente. Os dois tipos sofreriam medida de segurança? Para ambos seria esta eficaz? Ou ainda, há essa separação, ou por um entendimento mais complexo, não seriam as duas espécies de patologias uma só, inter-referentes e influenciadas entre si, condicionadas uma na outra?

Ainda, quanto à incompletude do desenvolvimento mental, citada pelo Código, se partirmos da premissa de que o indivíduo se constrói enquanto integrado aos demais, a medida de segurança seria (ou é) uma incongruência. Como "completar" esse 
desenvolvimento mental se ele está limitado às paredes do Hospital de Custódia (do Instituto Psiquiátrico Forense, no caso do Rio Grande do Sul)? A aprendizagem da vida em convívio social fica prejudicada e afastada, e o indivíduo, possivelmente, experimentará uma desintegração do organismo social a que ele pertence. Nesse teor:

Uma leitura psicanalítica não se refere ao indivíduo isolado, mas ao indivíduo em relação humana, inserido, portanto, no contexto social, já que o psíquico é social e o psiquismo é fenômeno da cultura. ${ }^{20}$

Tal reflexão valeria também para a tradicional e desgastada pena de prisão.

Merecida atenção especial, pela medida de segurança, ao criminoso com TPAS, faz-se salutar se resulta em eficácia. No âmbito da pena de prisão, possivelmente, esse indivíduo sofreria mais ainda, mantendo-se numa espécie de isolamento psíquico acerca da medida que lhe está sendo aplicada, ou seja, tal situação não melhoraria seu problema interno [isso de maneira geral, ressaltando que aqui não propomos tomar posicionamentos com juízos de certeza]. Já com a medida de segurança, calcada justamente nesse tratamento psiquiátrico, dependendo do andamento e condições do procedimento bem como de diversas circunstâncias pessoais do tratado, abrem-se horizontes para que a finalidade curativa seja alcançada.

A questão acerca da duração do internamento leva-nos a perceber sua perpetuidade inóspita, seja ocasionada pela metodologia do exame de sanidade, seja pela ineficácia do tratamento frente a determinado internado. Por isso a importância dos laudos e seu reflexo sobre as vidas subjugadas à sua valoração: liberdade ou prova de manutenção da doença. Voltamos à questão: o que seria um indivíduo normal?

Enfim, eficaz ou não, o sistema penal dá sinais de que sua aproximação com outras ciências, como a Psicologia, é essencial, ainda mais quando sopesados os objetivos de reinserção social do contingente dito "criminosos patológicos", ou com Transtorno de Personalidade Anti-Social. Trata-se de uma evolução, um aprimoramento da ciência criminológica moderna.

A partir do momento em que considerarmos que é a psique do indivíduo, em mútua interação interna e com o mundo exterior, que move o ser social e de que ela precisa ser cuidada e observada poderemos conseguir um pouco mais da ressocialização pretendida. Mudanças estruturais são necessárias, é claro, mas avanços na mentalidade daqueles que lidam com essa problemática do Direito Penal é o primeiro passo.

${ }^{20}$ FAGUNDES, José Otavio. et.al. Leituras psicanalíticas da violência. Orgnizadores Paulo César Sandler, et.al. Coleção Psicanálise, clínica, sociedade. São Paulo: Casa do Psicólogo, 2004, p. 21 


\section{DA IMPROPRIEDADE DOS TRATAMENTOS E SISTEMAS ATUAIS EM RELAÇÃO AO CRIMINOSO COM TRANSTORNOS DE PERSONALIDADE ANTI-SOCIAL}

A primeira crítica a ser feita, neste contexto, refere-se à capacidade técnica do juiz, principalmente no que diz respeito a criminosos com TPAS. Isso porque, devido a sua discricionariedade, pode o julgador contrariar as recomendações do laudo psiquiátrico, o que recorrentemente é feito, conforme já visto.

Entretanto, sendo, em grande maioria dos casos, bacharel em direito sem qualquer experiência em psicologia ou psiquiatria, a decisão judicial acaba por reger-se por motivos, no mais das vezes, políticos e morais. Isso porque são os crimes de tais agentes, via de regra, atos que chocam a sociedade [e esta clama por ver os "bandidos" presos], além de serem pessoas naturalmente odiosas, passíveis, portanto, de conquistar a antipatia de qualquer julgador.

Dessa forma, contrariando as recomendações dos psiquiatras [ao menos no que se refere aos do IPF de Porto Alegre], os criminosos com TPAS são enviados ao regime carcerário.

Não cabe aqui discutir as imensas falhas no sistema carcerário brasileiro, tais como superlotação, corrupção de policiais, atuação de crime organizado, etc, mas sim da ineficácia da pena de prisão como um todo, especialmente no caso em pauta. Conforme anota Cezar Bitencourt:

Quando a prisão converteu-se em resposta penológica principal, especialmente a partir do século XIX, acreditou-se que poderia ser um meio adequado para conseguir a reforma do delinqüente. (...) Esse otimismo inicial desapareceu e atualmente predomina uma certa atitude pessimista, já que não tem muitas esperanças sobre os resultados que se possa conseguir com a prisão tradicional. (...) Essa crise abrange também o objetivo ressocializador da pena privativa de liberdade, visto que grande parte das críticas e questionamentos que se faz à prisão, reerem-se à impossibilidade - absoluta ou relativa - de obter algum efeito positivo sobre o apenado. ${ }^{21}$

Ora, sabe-se que qualquer objetivo ressocializador por meio do recolhimento do apenado a regime carcerário está fadado ao insucesso. Isso porque, além de todos os defeitos retro mencionados dos quais um sistema carcerário é passível, há ainda fatores como o estigma que acompanha aqueles que já cumpriram pena de prisão, frente a uma sociedade que os repudia, bem como a estadia prolongada à margem da sociedade a que

\footnotetext{
${ }^{21}$ BITENCOURT, Cezar Roberto. Falência da Pena de Prisão - Causas e Alternativas. Ed. Revista dos Tribunais, São Paulo/SP, 1993, p. 143
} 
pertence, o que faz com que o apenado acabe por sair da prisão para um mundo que nunca conheceu e ao qual não está adaptado. Anota, novamente, Cezar Bitencourt (1993):

A segregação de uma pessoa do seu meio social ocasiona uma desadaptação tão profunda que resulta difícil conseguir a reinserção social do delinqüente, especialmente no caso de pena superior a dois anos. ${ }^{22}$

Além disso, é conhecido o fato de que, dentro das prisões há, invariavelmente, a criação de um sistema social isolado, à parte daquele conhecido pelo resto da sociedade. Lloyd Mccorkle e Richard Korn observaram as regras que se determinam o ambiente prisional:

1. Não há como fugir do sistema. O recluso encontra-se, não só fisicamente, encerrado, impedido de sair, como também se encontra preso a um contexto de comportamentos e usos sociais dos quais também não pode fugir.

2. Trata-se de um sistema extremamente rígido, onde a mobilidade vertical é muito difícil. (...)

3. O número de papéis que o indivíduo pode desempenhar é limitadíssimo e, depois de assumi-los, a tendência é mantê-los, especialmente quando representam os níveis mais baixos, mediante forte pressão do grupo.

4. As possibilidades que o indivíduo tem para selecionar seu papel são muito limitadas e condicionadas.

5. Desde o momento em que a pessoa ingressa na instituição, é submetida à influência do sistema social interno. ${ }^{23}$

Imagine-se, agora, o caso dos criminosos com TPAS, já totalmente alheios às ordenações morais da sociedade, em tal sistema. Beira o óbvio o fato de que não restará eficácia alguma à pena de prisão, exceto a preventiva, o que, contudo, restringe-se ao ambiente exterior à instituição carcerária e pelo limite de tempo da pena imposta.

Não há que falar-se em retribuição, posto que não há remorso, arrependimento, aprendizagem com os erros. Muito menos há que se falar em ressocialização, vez que já se está tratando com indivíduos marginais quanto a sua sociedade, além de estar-se tratando de um sistema que sequer consegue levar de volta à sociedade aqueles sem nenhuma patologia diagnosticada!

Infelizmente, é o que ocorre quando, no embate entre forças judiciais e médicas, as primeiras impõem sua autoridade garantida pela máquina estatal, em soluções tacanhas para problemas tão profundos. Isso, no Brasil, que conta com um sistema

\footnotetext{
${ }^{22}$ Ibidem, p. 147

${ }^{23}$ MCCORKLE, Lloyd; KORN, Richard. Ressocialization within walls, publicado no Readings in Criminology and Penology, University of Columbia Press, Estados Unidos, 1964, p. 189
} 
carcerário com gigantescos problemas além daqueles inerentes ao próprio sistema, é quase auto-destrutivo.

\section{CONSIDERAÇÕES FINAIS}

Bastaria, ao fim deste estudo, proferir a seguinte sentença: o Brasil não está pronto para os criminosos com TPAS. Seria simples, porém completamente vazio de sentido.

Isso porque, ainda que utilizando-nos de expressão pouco cabível, deve-se dizer que os criminosos com Transtorno de Personalidade Anti-Social já estão prontos para o Brasil. A falta de previsão de tratamento adequado não inibe a conduta. Não há a piedade da espera até que nosso sistema penal possa lidar com tal tipo de criminoso.

Sendo assim, é, inclusive de se perguntar: Quem está pronto? Certamente que não o está a pena de prisão. Ela meramente afasta o indivíduo da sociedade para largá-lo nela alguns anos mais tarde, após um "estágio" no qual este indivíduo é inserido em uma realidade totalmente diferente, estando também em contato com indivíduos igualmente perigosos e sem qualquer traço de remorso.

Não o está também o instituto tão afamado da Medida de Segurança. A verdade é que tal instituto, enquanto tratamento, pressupõe, por óbvio, um requisito básico: a possibilidade de ser tratado. Há possibilidade para toxicômanos, há também para esquizofrênicos. Para criminosos com TPAS, até onde se sabe, não há. São aparentemente imunes a terapias, tratamentos, análises. De resto, seria privação de sua liberdade tanto quanto na prisão, com a exceção da possível perpetuação da condição. E que seria o tolhimento da liberdade pelo tempo de uma vida, se descaracterizado do objetivo de tratamento, que não uma pena de prisão perpétua, expressamente proibida pela lei máxima de nosso ordenamento?

Paira, então, a pergunta [que certamente carece de muito mais estudo e reflexão interdisciplinares]: qual a solução? Que é esta maravilhosa instituição rígida que não é um manicômio judiciário [ou Instituto Psiquiátrico Forense] e nem uma penitenciária e que seria ideal para tal tipo de criminosos? Como alcançar a estrutura necessária para atingir-se uma solução?

Talvez quando respondidas estas e outras perguntas, o Brasil esteja pronto para os criminosos com TPAS.

\section{REFERÊNCIAS BIBLIOGRÁFICAS}


BIANCHINI, Alice; GOMES, Luiz Flávio.. O direito penal na era da globalização. Série "As ciências criminais no século XXI". São Paulo: Editora Revista dos Tribunais, 2002

BITENCOURT, Cezar Roberto. Tratado de Direito Penal - Parte Geral. 10 a ed. São Paulo: Saraiva, 2006.

FAGUNDES, José Otavio. et.al. Leituras psicanalíticas da violência. Orgnizadores Paulo César Sandler, et.al. Coleção Psicanálise, clínica, sociedade. São Paulo: Casa do Psicólogo, 2004.

CAPEZ, Fernando. Curso de Direito Penal - Parte Geral. 10 Edição. Ed Saraiva. 2006, São Paulo, SP.

MCCORKLE, Lloyd; KORN, Richard. Ressocialization within walls, publicado no Readings in Criminology and Penology, University of Columbia Press, Estados Unidos, 1964.

BITENCOURT, Cezar Roberto. Falência da Pena de Prisão - Causas e Alternativas. Ed. Revista dos Tribunais, São Paulo/SP, 1993, p. 143

CIPRIANI, Mário Luis Lírio. Das penas - suas teorias e funções no moderno direito penal. Ed. ULBRA, 2005, Canoas/RS, p. 51

SOUZA, Carlos Alberto Crespo de. CARDOSO, Rogério Göttert. Psiquiatria Forense 80 anos de prática institucional. Ed. Sulina. Porto Alegre, RS, 2006.

CANGUILHEM, Georges. O normal e o patológico. Ed. Forense Universitária. São Paulo, SP, 2001, p. 66

FREUD, Sigmund. O Ego e o Id. Ed. Imago. Rio de Janeiro, 1997, p. 96

HOSSEINI, Khaled. O caçador de pipas. Ed. Nova Fronteira. São Paulo, 2006, p. 45

CARRARA, Sérgio. Crime e Loucura - $O$ aparecimento do manicômio judiciário na passagem do século. Ed. UERJ. 1998, Rio de Janeiro, RJ 